\title{
Uma reflexão histórico- epistemológica da perspectiva social no campo da Ciência da Informação
}

\author{
Fellipe Sá Brasileiro * \\ José Mauro Matheus Loureiro ** \\ Gustavo Henrique de Araújo Freire ***
}

Artículo recibido:

31 de julio de 2013.

Artículo aceptado:

8 de agosto de 2013.

\section{Resumen}

Una reflexión bistórico-epistemológica de la perspectiva social en el campo de la Ciencia de Información. Se presenta una reflexión histórico-epistemológica de la perspectiva social en el campo de la Ciencia de Información, cuyo objetivo consiste en analizar la configuración social de las relaciones establecidas entre las asignaturas que han señalado su desarrollo teórico. La reflexión está construida bajo el análisis de las contribuciones de Otlet en el campo de la documentación y de los estudios de Bush en el ámbito de la recuperación de información en los EE UU, buscando encontrar una conexión con la perspectiva social contemporánea de producción de conocimiento en este campo. Se

* Universidade Federal da Paraíba, Brasil. fellipesa@hotmail.com

** Universidade Federal do Estado do Rio de Janeiro, Brasil. jmmloureiro@gmail.com

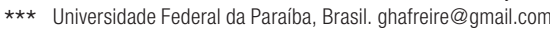


constata que el desarrollo social de la Ciencia de Información ha ocurrido con mayor evidencia por medio de relaciones interdisciplinarias con la documentación $\mathrm{y}$, en ritmo menor, con relaciones multidisciplinarias con las asignaturas exactas y de la naturaleza en la posguerra. Se concluye que el campo de la Ciencia de Información se caracteriza en el ámbito social por la existencia de relaciones interdisciplinarias y multidisciplinarias, siendo esta última encontrada con mayor frecuencia, todavía con posibilidades de volverse interdisciplinarias a lo largo del tiempo, teniendo en vista que la Ciencia de Información se configura como un campo flexible y propicio para la producción de nuevos conocimientos.

Palabras clave: Ciencia de información; Epistemología social; Documentación; Interdisciplinaridad; Multidisciplinaridad.

\section{Abstract}

\section{A historical-epistemological reflection of the social perspective in the field of Information Science \\ Fellipe Sá-Brasileiro, José Mauro Matheus-Loureiro and Gustavo Henrique de Araújo-Freire}

This paper offers a historical-epistemological reflection of the social perspective in the field of Information Science and provides an analysis of the social configuration of the diverse disciplines influencing its theoretical development. The reflection is constructed through an analysis of Otlet's contributions to the field of documentation field and Bush's work in information retrieval in the United States, while attempting to discern associations with contemporary social perspective of knowledge theory. The study confirms that there is more evidence for the social development of Information Science occurring through interdisciplinary relationships with the documentation and, to a lesser degree in the post-war period, through multidisciplinary relationships in the exact and natural sciences We conclude that the social environment, of the field of Information Science is characterized by the existence of inter-disciplinary and multi- disciplinary relationships, the latter of which is most common; though such relationships retain the potential for becoming 
interdisciplinary in nature over time, since the field of Information Science is elastic and conducive to the production of new knowledge.

Keywords: Information Science; Social Epistemology; Documentation; Interdisciplinary; Multidisciplinary.

\section{INTRODUÇÃO}

ão expressivas as discussões contemporâneas sobre o campo da Ciência $\checkmark$ da Informação voltadas para a compreensão de sua origem, cientificidade e possibilidades de aplicação na sociedade em que vivemos. Alguns trabalhos relatam que o reconhecimento e registro teórico oficial da Ciência da Informação como campo científico data do início da década de 1960, especificamente no Georgia Institute of Technology no Estado da Georgia, nos Estados Unidos (EUA), quando um grupo de professores e bibliotecários da própria universidade se reuniu para tratar de assuntos inerentes ao treinamento de especialistas da informação, em âmbito local, na conferência que ficou conhecida como Conferences on training science information specialists.

Entretanto, o relato deste acontecimento, por si só, não chega a constituir o marco indicador do surgimento do campo da Ciência da Informação, haja vista que outras manifestações importantes que eclodiram em épocas anteriores, em países distintos, contribuíram de forma significativa para a criação de um espaço próprio de atuação deste campo do saber. Estas manifestações foram impulsionadas por meio da explosão informacional germinada no contexto das revoluções científicas e tecnológicas sucedidas entre os Séculos XVI e XIX, e intensificada na segunda metade do Século XX, principalmente por ocasião dos desfechos da Segunda Guerra Mundial.

Nesse contexto, é possível abordar o campo da Ciência da Informação por diferentes prismas ao longo de sua história, tendo em vista os caminhos distintos que se propôs a seguir na procura de se consolidar como ciência, sendo estes capazes de demonstrar agora, pela análise dos vestígios de seus traçados, a configuração do que seria para os estudos da navegação: as rotas de loxodromia ${ }^{1}$ e ortodromia. ${ }^{2}$ Enquanto a loxodromia corresponde à ma-

1 Linha constante entre dois pontos que mantem o mesmo ângulo de navegação entre o rumo seguido e os meridianos.

2 Círculo máximo que corresponde ao caminho mais curto entre dois pontos, mas que precisa ser ajustada constantemente para que não venha a perder o rumo da navegação. 
neira mais distante de navegação, porém menos complexa (tendo em vista necessitar apenas de um único alinhamento entre o ângulo de partida com o norte para cruzar os meridianos do globo terrestre na mesma inclinação), a ortodromia consiste no caminho mais rápido de navegação, todavia com maior nível de complexidade (devido à constante necessidade de se fazer ajustes precisos na angulação entre os meridianos durante a navegação, o que aumenta a possibilidade de distanciamento do rumo correto).

Partindo deste princípio metafórico, no decorrer do desenvolvimento científico, alguns estudos do campo da informação optaram por caminhos mais curtos de navegação, enquanto outros permaneceram, na medida do possível, em rotas mais lentas, porém constantes. No entanto, compreendese que ambas as vertentes se encontraram em alguns ângulos que marcaram o caminho, da mesma forma que outros se afastaram temporariamente em direção a rumos opostos, devido à aplicação de azimutes ${ }^{3}$ distintos, até finalmente convergirem na contemporaneidade para um só ponto de chegada: o ponto de vista social. Nesta odisseia, várias disciplinas deixaram suas contribuições para a formação da identidade da Ciência da Informação, sendo algumas com maior participação, outras com menor evidência. Algumas deixaram e levaram consigo valiosos conhecimentos, outras partiram da mesma forma que chegaram, mas todas com perspectivas de mudança.

Nesse sentido, faz-se necessário desenvolver uma reflexão epistemológica a respeito desses encontros e desencontros disciplinares ao longo de sua história, partindo das contribuições de Otlet no campo da Documentação, seguindo para os feitos de Bush no âmbito da recuperação da informação norte-americana para que, a partir de então, torne-se possível encontrar os ângulos de conexão com a perspectiva social contemporânea de produção do conhecimento. Portanto, sem o caráter de delimitação de paradigmas ou categorias, este artigo tem como principal objetivo analisar as disciplinas que contribuíram para o desenvolvimento social do campo da Ciência da Informação, bem como as características de suas relações e contribuições, levando em consideração que a Ciência da Informação constitui um campo flexível e propício para a produção de novos conhecimentos, desde que o objetivo de navegação seja sempre ampliar novos horizontes. 


\section{A DocumentaÇÃo de OTLET: PONTO DE PARTIDA DA CIÊNCIA DA INFORMAÇÃO}

Os trabalhos desenvolvidos por Paul Otlet e Henri La Fontaine no campo da Documentação, iniciados ainda no final do Século XIX, em Bruxelas, foram fundamentais para o desenvolvimento do campo da Ciência da Informação. O início desta contribuição se deu com a criação do Instituto Internacional de Bibliografia (IIB), em 1985, de onde Pinheiro (1997, p. 28) afirma ter surgido a ideia de "bibliografia como registro, memória do conhecimento científico, desvinculada dos organismos, entre os quais arquivos e bibliotecas, e não relacionada a acervos ou coleções". É importante lembrar que antes disso, a tradicional atividade de bibliografia se concentrava nos processos relacionados ao livro, desconsiderando os demais suportes documentais. Logo, por sugestão dos autores, o termo bibliografia foi substituído pelo de Documentação, o qual abrangeria o trabalho com o conteúdo informacional existente nos diferentes tipos de suporte.

Com efeito, esta Documentação influenciou a construção de um conceito de informação para o campo da Ciência da Informação, cunhado pelo estadunidense Buckland (1991) que, após definir a informação como "coisa" para compreender todo objeto potencialmente informativo (pessoas, documentos, produtos, mensagens, eventos, objetos de museus, etc.), esclarece sua real pretensão em outro trabalho publicado ainda neste ano que enfatiza a informação (coisa) no contexto da comunicação, isto é, considerando que a informação está situada nas práticas estabelecidas pelos sujeitos. Rayward (1994), reconhecido por traduzir e comentar os principais trabalhos de Otlet, assegura que esta forma de pensar a respeito da informação, de maneira discursiva, é fruto das ideias novelescas e práticas da Documentação de Otlet no decorrer do final do Século XIX e início do Século XX que, sem dúvidas, corroboraram para a constituição de um novo meio de pensar sobre o que chamamos de Ciência da Informação.

Já nesta época, Otlet, em parceria com La Fontaine, estava preocupado com a universalização do conhecimento humano, isto é, com a disponibilização em rede da informação registrada nos diversos suportes documentais (livros, relatórios científicos, filmes, microfilmes, fotografias, rádios, desenhos industriais, etc.) e armazenada nos tradicionais centros de informação (bibliotecas, arquivos, museus, etc.), para todos os países do mundo. Para tanto, os autores criaram, com base na Classificação Decimal de Dewey (CDD), o Repertório Bibliográfico Universal (RBU) que, em síntese, constituía um imenso catálogo atualizado, composto por uma base de dados em fichas integradas, as quais continham obras referentes a todos os países do universo. 
As ideias "visionárias" de Otlet representam as primeiras manifestações de caráter resolutivo para um problema de informação contemporâneo. Freire (2006, p. 9) destaca que, na concepção de Otlet, "tornava-se necessário ordenar essa Documentação de modo a dar uma resposta ao que lhe parecia o problema central de toda e qualquer sociedade", o qual consistia em "como proceder para que o conhecimento registrado estivesse disponível para quem dele tivesse necessidade". O estudioso compreendia que a informação, uma vez recuperada, seria capaz de provocar uma comunicação intelectual e, por conseguinte, a mudança social e a paz mundial, haja vista que o acesso à informação organizada possibilitaria a formação de uma opinião pública internacional e democrática.

Vislumbra-se então que estas pretensões de Otlet relacionadas à disponibilização da informação registrada em rede, de forma rápida, atualizada e acessível para um grande número de pessoas, configuram-se como os rascunhos antecessores, ou até mesmo como um incipiente protótipo do que seria para hoje, em pleno Século XXI, os sistemas de informação na rede de alcance mundial World Wide Web, como por exemplo, o Google e o Facebook. De acordo com Figueiredo (1996, p. 16), o termo "Documentação" corresponde na verdade a "um neologismo, criado por Otlet, para designar o que hoje em dia tendemos a chamar de armazenamento e recuperação da informação". Sendo assim, o revolucionário Tratado de Documentação cunhado por Otlet (1934) teria em seu escopo a finalidade de propor a construção de "novos tipos de sistemas mecânicos integrados para o manejo da informação, os quais ainda teriam de ser inventados e transformariam o meio ambiente e as práticas dos pesquisadores" (Figueiredo, 1996, p. 16).

Destarte, acredita-se que o advento das grandes guerras mundiais no limiar do Século XX atrapalhou as pretensões de Otlet no campo da Documentação, retirando a perspectiva europeia do cenário científico da informação durante anos e, principalmente, adiando o desenvolvimento amplo da Ciência da Informação em relação às práticas de comunicação e conhecimento que se configuram como problemas da sociedade contemporânea. No período entre as guerras, autores estadunidenses que possuíam fortes ligações com Otlet, tais como Watson Davis e Samuel Bradford, apropriaram-se de algumas inovações do campo da Documentação e colocaram os Estados Unidos como protagonista do que seria o estado da arte das pesquisas realizadas na Europa. Todavia, a ênfase dos estudos se restringia ao desenvolvimento de técnicas melhoradas e tecnologias para o provimento do acesso a bibliografia científica (Tiratel, 2008).

Nesse contexto, o despertar científico para a atividade de informação que ora despontara como importante para o setor estratégico-militar influenciou 
o surgimento do que viria a se configurar como os construtos tecnológicos propostos por Otlet. A partir do desencadeamento da Segunda Guerra Mundial, no momento em que os processos atrelados à informação, sobretudo os que envolviam o armazenamento, a organização e a distribuição da informação científica, passaram a ser analisados como recurso estratégico por países envolvidos em conflitos ideológicos, dá-se início ao aumento desenfreado da produção de pesquisas científicas, concomitantemente ao desenvolvimento de novas tecnologias de informação e comunicação.

\section{A PERSPECTIVA de Bush (I945): RUMO A CONSTRUÇÃO DO CAMPO CIENTÍ́FICO}

Dentre as pesquisas científicas realizadas no período do pós-guerra, destaca-se o trabalho publicado em 1945, no Atlantic Montthly, por Vannevar Bush, respeitado cientista do Instituto de Tecnologia de Massachussets (MIT) e chefe do esforço científico americano durante a Segunda Guerra Mundial. A partir da publicação do artigo intitulado "As we may think" (Como podemos pensar), Bush apresenta o grande problema relacionado ao armazenamento e à recuperação da informação, causado pela explosão informacional e, de forma singular, propõe uma solução baseada em tecnologias de informação e comunicação (TIC). A proposta seria a criação de um dispositivo para uso individual, denominado por ele de MEMÉX, pelo qual se compunha de um aparelho capaz de armazenar, por meio de um processo mecanizado, os registros e demais documentos de um determinado usuário, tais como livros, fotos, jornais e revistas, de modo que estes poderiam ser consultados com extrema velocidade e flexibilidade, aproximando-se do que seria, para os dias atuais, a tecnologia de um sistema de computador em rede.

Com pioneirismo, a ideia de Bush (1945), atinente ao gerenciamento da informação com fundamentos em Ciência e Tecnologia, incitou o mundo acadêmico, governantes e órgãos de Estado, no que diz respeito ao desenvolvimento de programas estratégicos para o efetivo controle da explosão informacional. Nesse contexto, o fenômeno da informação passou a ganhar relevância no âmbito da sociedade, vindo posteriormente a se tornar o ensejo de inúmeras reflexões científicas. Pinheiro (2002, p. 73) reconhece que isto ocorreu porque "Bush teve a clara percepção do elo entre informação e pesquisa e desenvolvimento e, consequentemente, do seu valor político e estratégico”.

Compreende-se então que o despertar do interesse científico na busca de soluções para os problemas relativos ao processo de armazenamento e recuperação da informação, conforme evidenciado nos estudos de Bush (1945), 
corresponde a um dos principais fatores que sinalizaram a necessidade do campo científico da Ciência da Informação. Por outro lado, constata-se também que este empenho foi capaz de viabilizar o desenvolvimento das modernas tecnologias de informação e comunicação (TIC), que hoje se configuram como a essência da formação social contemporânea.

Do ponto de vista da institucionalização do campo científico, foi a partir do período do pós-guerra de 1948, sendo este caracterizado pela disposição da informação produzida e acumulada durante a Guerra para toda a sociedade, em que as reflexões provenientes dos problemas causados pelo enorme fluxo informacional (no que tange o armazenamento, organização e distribuição da informação), trouxeram os primeiros esclarecimentos para os questionamentos de cunho acadêmico, os quais foram condicionantes para o consentimento da atividade de informação como ciência, isto é, para a construção do campo científico da Ciência da Informação (Barreto, 1992).

Simultaneamente a estas reflexões, algumas correntes teóricas surgiram na intenção de conceber um conceito para a informação dentro da perspectiva científica. Dentre elas, as que obtiveram maiores repercussões foram a Teoria Matemática da Comunicação, conhecida também como "Teoria da Informação", apresentada por Shannon e Weaver em 1948 e publicada em 1949; e a Teoria Sistêmica da Informação, originada na década de 1930 por Bertalanffy, porém reconhecida em maiores proporções após a publicação do trabalho de Wiener, em 1948, denominado Cybernetics or control and communication in the animal and the machine.

A Teoria da Informação proposta por Shannon e Weaver (1949) é construída a partir da preocupação com a eficácia do processo de comunicação, especificamente com os problemas técnicos relativos ao transporte físico da materialidade que compõe a informação. Para tanto, os autores apresentam pela primeira vez um enunciado científico para a informação, o qual reflete o início do tratamento da informação como ciência. No referido estudo, Shannon e Weaver priorizam uma noção linear do processo de comunicação, descartando a subjetividade como elemento componente da informação, ou seja, consideram a informação como um fenômeno objetivo independente dos sujeitos que com ela se relacionam e, portanto, passível de ser estudada “cientificamente” (Araújo, 2009).

Por outro lado, a Teoria Sistêmica da Informação publicada no trabalho de Wiener (1948), originária das Ciências Biológicas e aplicada em diversos tipos de estudos, apresenta um modelo baseado no organismo humano, onde uma determinada parte pertencente a uma estrutura exerce sua função de maneira específica contribuindo para o desenvolvimento do todo. De modo contrário à Teoria Matemática da Comunicação, a qual preza pela lógica li- 
near do processo, o modelo sistêmico prioriza o princípio cíclico do processo, uma vez que considera que a saída (output) de um elemento do processo provocará a formação de novos elementos de entrada (input). Diante de uma visão técnica do modelo sistêmico, como é o caso da recuperação da informação, os estudos relacionados aos sistemas de informação são ponderados a partir da lógica de três processos: os de entrada (entrada de dados, com a aquisição de itens informacionais, a seleção destes itens para a composição de determinado acervo), de processamento (os itens informacionais que dão entrada num sistema de informação precisam ser descritos, catalogados, classificados e indexados) e de saída (pelo acesso aos itens informacionais por parte dos usuários na forma de disseminação, entrega da informação, empréstimo, etc.) (Araújo, 2009).

Ambas as teorias fundamentadas nas ciências da natureza, exatas e tecnicistas, as quais mantêm seus esforços voltados para os preceitos da objetividade, neutralidade e matematização, foram fundamentais para a formação do estatuto científico da Ciência da Informação, mesmo que este tenha negligenciado o contexto de significado e de relevância que envolve o uso da informação por humanos. A primeira contribuiu para a idealização dos conceitos de ruído, entropia e redundância, os quais são fundamentais nos estudos dos sistemas de recuperação da informação, além de diferenciar a concepção de informação e mensagem ao perceber que a informação pode ser desvinculada de qualquer suporte físico (Pinheiro, 2002). Já a segunda, responsável pela teoria funcionalista, no que se refere à função da informação na sociedade, influenciou a preocupação dos estudiosos da área da informação científica sobre a importância do papel dos centros de informação (bibliotecas, museus, arquivos, etc.) para a sobrevivência e manutenção de domínios específicos da sociedade, tais como universidades, organizações e comunidades específicas (Shera, 1970).

Contudo, não se pode ignorar que as bases teóricas para o advento da Ciência da Informação, assim como o delineamento do objeto central deste campo do conhecimento já haviam sido fincadas em períodos anteriores, através dos trabalhos desenvolvidos por Paul Otlet com o apoio de Henri La Fontaine. Estes trabalhos, além de terem possibilitado as primeiras compreensões da informação como um fenômeno social, capaz de gerar mudanças no ambiente social, abriram espaço para os estudos voltados para a obtenção do acesso à informação em nível global, pelos quais decorreram as ideias relacionadas ao desenvolvimento de novas tecnologias para a disponibilização dessa informação.

A partir do exposto, percebe-se que a configuração de origem da Ciência da Informação se apresenta sob duas perspectivas de abordagem: a) os 
estudos no campo da Documentação voltados para o compartilhamento em rede do conhecimento registrado para fins de desenvolvimento humano em nível mundial, conforme podem ser observados os trabalhos realizados por Paul Otlet; b) as pesquisas realizadas por Vannevar Bush no âmbito da recuperação da informação, voltadas para o desenvolvimento de tecnologias de gerenciamento da informação científica em nível estratégico que, por conseguinte, incitaram a criação de teorias que deram caráter científico à atividade de informação e ao campo.

\section{REFLEXÕES EPISTEMOLÓGICAS DA PERSPECTIVA SOCIAL DA CiÊNCIA DA INFormaÇÃo}

Sem dúvida, a perspectiva estadunidense iniciada por Bush (1945) se sobrepôs a europeia de Otlet durante longos anos, bem como a outras que emergiram no pós-guerra em outros países ${ }^{4}$, principalmente após a publicação estratégica do artigo de Borko (1968) no periódico American Documentation que, ancorado nos estudos de Robert Taylor, consagrou a definição clássica de Ciência da Informação na comunidade acadêmica:

Ciência da Informação é a disciplina que investiga as propriedades e o comportamento da informação, as forças que regem seu fluxo e os métodos para processá-la, a fim de obter acessibilidade e utilização ótimas. Está interessada num conjunto de conhecimentos relacionados com a origem, coleção, organização, armazenamento, recuperação, interpretação, transmissão, transformação e utilização da informação. Inclui a investigação das representações da informação nos sistemas naturais e artificiais, a utilização de códigos para a transmissão eficiente da mensagem, o estudo de instrumentos e técnicas de processamento da informação, tais como computadores e seus sistemas de programação. É uma ciência interdisciplinar [...] relacionada com a matemática, a lógica, a linguística, a psicologia, a tecnologia de computação, a pesquisa operacional, as artes gráficas, a comunicação, a biblioteconomia, a administração [...] Tem componentes de uma ciência pura, que investiga o assunto sem relação com sua aplicação, e componentes de uma ciência aplicada, que cria serviços e produtos. (Borko, 1968, p. 3)

Tal definição, marcada pelo pensamento empirista e positivista dominante naquele momento, representa um esforço estadunidense para responder, de forma antecipada, as possíveis questões de cientificidade do campo, tais como a delimitação de um objeto de estudo (informação), bem como sua 
configuração disciplinar (interdisciplinaridade). Além disso, ao abranger a criação de serviços e produtos como características do campo, contempla de forma indireta os interesses capitalistas da indústria de informação do país que, por meio de pesquisa e desenvolvimento em tecnologias de recuperação da informação, revolucionou as formas de comunicação e a dinâmica social em nível mundial. Para Rabello (2012, p. 14), esta definição apresentada por Borko enfatiza a tecnologia e os recortes teórico-disciplinares "sob o ponto de vista prático e tecnicista em detrimento da contextualização do pensamento produzido na CI numa tradição científica e filosófica”, isto é, corroborando para uma inconsistência teórica até hoje.

Além disso, é possível dizer que o distanciamento dos aspectos sociais e culturais no discurso dominante do campo da informação representa o principal motivo para a longevidade dos problemas teórico-metodológicos da Ciência da Informação no decorrer do Século XX. Compreende-se que mesmo após as primeiras manifestações de mudança da ênfase do ponto de vista empirista e positivista entre as décadas de 1980 e 1990, a partir da introdução da abordagem cognitiva que considera os aspectos subjetivos do indivíduo nos processos de comunicação e recuperação da informação, com destaque para Belkin e Ingwersen, as relações sociais e estruturas sociais permaneceram em segundo plano, cedendo o lugar principal para os estudos de modelos mentais (mentalismo) dos usuários de informação com vias para a concepção de sistemas de recuperação de informação mais eficazes (Cronin, 2008).

No início do Século XXI, as reflexões teórico-epistemológicas que analisam os processos de produção do conhecimento no âmbito da Ciência da Informação passam a dar ênfase aos aspectos sociais e culturais da informação na sociedade contemporânea, bem como na influência das ciências sociais sob as novas formas de produção de conhecimento. No entanto, é importante ressaltar que a abordagem social sempre esteve presente no cenário informacional, mesmo que em segundo plano por um longo período e, por que não dizer, em posição de destaque em alguns momentos, como é o caso da epistemologia social proposta por Shera (1970) que, fundamentada no escopo das ciências sociais, considera que a produção da informação e do conhecimento é proveniente do contexto social e cultural específico que recebe interferência dos processos da comunicação humana.

Cronin (2008), ao fazer uma revisão da abordagem social na Ciência da Informação resgata alguns autores importantes, como por exemplo, o estadunidense Butler (1933) que, ainda antes dos feitos de Bush (1945), no campo da Biblioteconomia, desenvolveu a ideia de uma "ciência da biblioteca" voltada para o estudo dos problemas sociais de intercâmbio de informações 
e comunicação na sociedade que, por sua vez, influenciou o próprio termo “epistemologia social”, cunhado por seu aluno Shera (1970). Da mesma forma, destaca-se o trabalho de Kling (1990) que defende a informática social como o estudo interdisciplinar do desenho, usos e consequências das tecnologias de informação que leva em conta a sua interação com contextos institucionais e culturais.

As ideias de Butler (1933) desenvolvidas no início do Século XX, nos Estados Unidos, no período em que as ideias de Otlet (1934) revolucionavam o campo da Documentação, na Europa, sinalizam uma crítica ao campo da Biblioteconomia norte-americana no esforço de superar a visão pragmática dominante, relacionada à mera aplicação das práticas biblioteconômicas, para dar lugar à reflexão científica sobre os fenômenos sociais que incidiam na constituição dos problemas do campo. Nesse sentido, enquanto a reflexão teórica de Butler (1933, p. 71) acreditava que a atividade da Biblioteconomia deveria estar voltada para "a transmissão da experiência acumulada pela sociedade, a cada um de seus membros, por meio da instrumentalidade do livro", o pragmatismo de Otlet (1934) vislumbrava as possibilidades de compartilhamento em rede deste conhecimento registrado nos livros e nos demais suportes documentais para todos os cidadãos do mundo.

Apesar de ambas as perspectivas estarem enraizadas no paradigma empirista e positivista dominante, observa-se que tanto as reflexões teórico-epistemológicas de Butler quanto às propostas de Otlet para a resolução de problemas de informação estão voltadas para o contexto social dos campos da Biblioteconomia e da Documentação, respectivamente. Para Tiratel (2008, p. 16), em conformidade com Day (1997), a natureza aplicada do trabalho de Otlet "aborda um tipo particular de idealismo pragmático dentro da modernidade tardia”. É o que Ducheyne (2005) explica ao enfatizar que a influência do positivismo de Otlet não é uma questão de tudo ou nada, pois sua concepção do conhecimento científico se diferencia do que poderia ser considerado como uma epistemologia positivista.

Ora, as manifestações do positivismo não somente devem ser consideradas sob a ótica da dominação tradicional, isto é, racional, neutra ou quantitativa, mas também sobre o viés institucional no sentido amplo de legitimidade, haja vista que suas formas de pensar, em contextos distintos, fizeram com que as reflexões sociais dos séculos passados fossem inseridas no âmbito da ciência, o que possibilitou as primeiras contribuições relevantes para as ciências do social, na contemporaneidade, como por exemplo, as de Otlet no campo da Documentação que refletem para hoje os ideais de uma Ciência da Informação. 
Nesse sentido, este breve resgate histórico-epistemológico da perspectiva social no campo da informação demonstra que no período que antecede o legado de Bush (1945), as bases teóricas e práticas da Ciência da Informação contemporânea já estavam delineadas no âmbito social, mesmo que ainda distantes de pretensões de cientificidade para uma Ciência da Informação, incitando a reflexão de que o desenvolvimento teórico-metodológico do campo poderia ter seguido um curso diferente caso as reflexões e as práticas de informação tivessem resistido aos acontecimentos sociais sucedidos ao longo do Século XX, como por exemplo, as duas grandes guerras, bem como ao pensamento científico que se tornou dominante. Já era possível pensar, naquele momento, que a Ciência da Informação se constituiria como: uma área do conhecimento que estuda o fenômeno da informação no contexto social, quando a informação for agenciada por atores sociais, com o intuito de resolver problemas de informação ou refletir sobre a origem destes problemas, sejam eles científicos ou não.

\section{A CONVERGÊNCIA ENTRE AS ROTAS: O RUMO SOCIAL}

Foi necessário esperar longos anos para que o pensamento sobre a Ciência da Informação se aproximasse do que seria a base social para o desenvolvimento do campo. Com efeito, o estadunidense Saracevic (1996) apresenta, no final do Século XX, outra definição clássica para a Ciência da Informação que, ao mesmo tempo em que preservava todos os esforços norte-americanos no âmbito da recuperação da informação na segunda metade do Século, resgatava as questões da comunicação do conhecimento registrado para as pessoas no contexto social, sendo estas, as bases das ideias de Butler e Otlet:

A Ciência da Informação é um campo dedicado às questões científicas e a pratica profissional voltadas para os problemas da efetiva comunicação do conhecimento e de seus registros entre os seres humanos, no contexto social, institucional ou individual do uso e das necessidades de informação. No tratamento destas questões são consideradas de particular interesse as vantagens das modernas tecnologias informacionais. (Saracevic, 1996, p. 47)

Esta definição, concebida logo após o período que marcou o enfoque cognitivista na produção do conhecimento científico da Ciência da Informação, entre os anos de constantes tentativas de abandono dos cânones positivistas e inserção do indivíduo nos processos de informação, é uma forma de acompanhar a mudança no domínio do conhecimento do campo iniciada no 
final do Século XX que, de maneira tardia, passou a enfatizar o estudo científico da comunicação da informação na sociedade. De acordo com Linares Columbié (2010), o problema central deste novo domínio do conhecimento se refere à "questão de facilitar a comunicação efetiva da informação entre produtor e usuário", tendo como os primeiros sinais de mudança as enormes críticas protagonizadas por Birger Hjørland e Brend Frohmann no que diz respeito à hegemonia da abordagem cognitiva.

Hjørland $(1995 ; 2002)$ apresenta uma proposta de assumir a visão cognitiva na perspectiva das comunidades discursivas que produzem, trocam e consomem conhecimento a partir da interação com o contexto histórico, social e cultural. Nesse sentido, sua visão sociocognitiva tende a dar tratamento epistemológico aos processos cognitivos relacionados com a produção e comunicação do conhecimento num campo de domínio, de modo a levar em consideração tanto as circunstancias externas quanto internas que influenciam a interpretação e o agir do indivíduo. Para Linares Columbié (2010), a análise de domínio não corresponde a uma "orientação de caráter paradigmático na Ciência da Informação, mas tem se destacado por ser um discurso com pretensões abarcadoras nos campos teóricos e práticos".

Por outro lado, Frohmann $(1995 ; 2008)$ se afasta da epistemologia baseada na perspectiva de realidade interna do indivíduo e enfatiza que o conhecimento se constrói a partir da prática fundamentada no mundo material. Inicialmente, na intenção de propor um objeto de estudo para a disciplina de políticas de informação, Frohmann (1995) elenca as práticas informacionais exercidas no contexto da rádio aberta ou Internet como o novo domínio do poder informacional em detrimento do poder tradicional exercido pelo estado, governo ou bibliotecas, configurando assim o que ele denomina de regime de informação. ${ }^{5}$

Em seguida, ao enfatizar as práticas documentárias para a compreensão do que seria a materialidade, Frohmann (2008) se apropria do pensamento de Foucault sobre a materialidade dos enunciados no sentido de alargar o campo de análise dos possíveis regimes de informação. De forma peculiar, Foucault discute o enunciado pela via de sua existência: como ele surge, as regras de sua transformação, ampliação, as conexões entre enunciados, e seu deixar de existir. Compreende-se então que a materialidade é medida pela massa, energia e força, em um processo dinâmico de estabilização e desestabilização que reflete os níveis de poder. Dessa forma, Frohmann quer dizer que existe um caminho direto a partir da análise dos enunciados de Foucault

5 “[...] qualquer sistema ou rede mais ou menos estável na qual a informação flui através de determinados canais de produtores específicos, através de estruturas organizacionais específicas, para consumidores e usuários específicos” (Frohmann, 1995, pp. 5-6). 
para o estudo da materialidade da informação, tendo a Documentação como o conceito de ligação que, em meio de práticas documentais científicas, institucionais ou tecnológicas, adquire massa, inércia e estabilidade capaz de materializar a informação de tal forma que ela possa configurar profundamente a construção do conhecimento e a vida social.

Assim, observa-se que ambas as perspectivas -Hjørland e Frohmannresgatam e consolidam a abordagem social neste novo panorama da produção do conhecimento na Ciência da Informação. No entanto, a abordagem de Frohmann $(1995$; 2008) apresenta um olhar específico do fenômeno da informação voltado para a análise dos efeitos dos regimes de informação que, através das práticas informacionais/documentárias e dos aparatos tecnológicos, modificam os processos de comunicação e conhecimento da estrutura social contemporânea. Sendo assim, ao enfatizar a questão dos efeitos dessa informação imbricada nas tecnologias no âmbito da sociedade em sobreposição as questões tradicionais que conduzem o estudo da informação como commodities sob a ótica da economia e do mercado, a abordagem de Frohmann abre espaço para a concepção de outras dimensões do objeto informacional na estrutura social contemporânea, para além do conhecimento produzido pelo homem, principalmente quando se permite integrar o avanço das tecnologias digitais aos estudos epistemológicos de natureza social, política, econômica e cultural.

Após esta compreensão de Frohmann sobre o regime de informação, outras reformulações do conceito foram sucedidas no âmbito da política e do poder, sem estarem restritas aos efeitos das práticas documentárias, sendo ampliadas, conforme González de Gómez (2012, p. 56), para as “ações e interações de coletivos engajados em situações e circunstâncias, ancorados no tempo, no espaço e nas condições de produção e reprodução social da vida", com ênfase nas dinâmicas antes que nas estruturas, associadas aos "contextos regulatórios e tecnológicos que intervém e perpassam diferentes domínios de atividade, agências e organizações”. Dentre as diferentes perspectivas, destacam-se os trabalhos da própria González de Gómez (1999; 2002), como também de Braman (2004) que aborda a ideia de um único regime global e emergente de informação para os estudos das políticas de informação e, posteriormente, de Ekbia (2009) que retoma o conceito de regime de informação com base nas relações entre informação e ação, ressaltando que as práticas de informação estão situadas em contextos sociais distintos, alinhando-se com a concepção de Buckland (1991) sobre o conceito de informação (situada) no campo da Ciência da Informação.

Nesse sentido, de acordo com González de Gómez (2007, p. 57), “a Ciência da Informação pode integrar, juntamente com a epistemologia, um cam- 
po de explicações das formações sociais inerentes ao novo estatuto do conhecimento”. Uma das características da sociedade contemporânea diz respeito à redução dos espaços discursivos e institucionais da epistemologia, bem como ao aumento das atividades dedicadas a pesquisa e desenvolvimento de tecnologias de informação. Assim, com base na visão da autora, o regime de informação passa a se apresentar como o substituto dos demais regimes, cabendo à Ciência da Informação a finalidade de definir tudo aquilo que pode ser chamado de informação, da mesma forma que à reflexão epistemológica, o esclarecimento das condições de possibilidade de um conhecimento da informação que possa se chamar de científico.

Portanto, acredita-se que a relação entre a pesquisa prática e a reflexão epistemológica no campo da Ciência da Informação, circunstancialmente rompida no decorrer da Segunda Guerra Mundial deve se fortalecer no contexto científico contemporâneo sob o viés da perspectiva social, esclarecendo as questões informacionais que se renovam com o avanço desenfreado das tecnologias digitais, ampliando os horizontes do conhecimento científico da informação e, principalmente, resolvendo problemas de informação da vida prática.

Com base nas reflexões histórico-epistemológicas contextualizadas até aqui, levando em consideração que as bases teóricas da Ciência da Informação se devem ao contexto sociocultural da informação e do conhecimento, vislumbra-se a oportunidade de discutir as relações estabelecidas entre a Ciência da Informação e as demais disciplinas que historicamente estiveram presentes nos discursos científicos do campo, buscando analisar através das características sociais que configuram o viés da resolução de problemas e da produção de novos conhecimentos, respectivamente, a noção de multidisciplinaridade e interdisciplinaridade.

\section{Os ÂNGULOS DE ENCONTROS (RELAÇÕES)}

\section{INTERDISCIPLINARES E MULTIDISCIPLINARES}

Este assunto de cunho disciplinar apresenta certa densidade em sua abordagem, encontrando vários entendimentos no âmbito da Ciência da Informação. Holland (2008, p. 8) reconhece que a utilização dos termos interdisciplinaridade e multidisciplinaridade dentro do campo da Ciência da Informação apresentam grande confusão de conceituação, principalmente por ocasião do desconhecimento dos próprios pesquisadores sobre as peculiaridades de seus significados. Na maioria das vezes, estes termos são empregados de forma indevida na aplicação das pesquisas, sobretudo como sinônimos, baseados em suposições de significados imprecisos. 
No que se refere às relações de natureza interdisciplinar, os autores Klein e Newell $(1998$, p. 3) consideram que esses estudos podem ser definidos como um processo que objetiva responder a um questionamento, resolver um determinado problema, ou abordar um tema que é muito amplo ou complexo para ser tratado de forma adequada por uma única disciplina ou profissão. Para que isso ocorra, tal processo se estabelece por meio da integração de conhecimentos e métodos pertencentes a outras disciplinas que, por sua vez, poderão contribuir com transformações ou até mesmo com a produção de novos conhecimentos. Por outro lado, no que tange as relações de natureza multidisciplinar, Moran (2002, p. 16) parte da concepção de que este tipo de colaboração se refere simplesmente à justaposição de duas ou mais disciplinas, ou seja, a aproximação entre diferentes disciplinas que ao desempenharem um trabalho lado a lado, auxiliam na resolução de um determinado problema sem a finalidade de transformar ou produzir novas formas de conhecimento.

Nesse sentido, compreende-se que a colaboração de natureza interdisciplinar é caracterizada pela sua capacidade de modificar ou de produzir novos conhecimentos de forma consistente no decorrer das relações, por meio do intercâmbio de conceitos, teorias e métodos específicos pertencentes a cada disciplina, ao passo que a colaboração multidisciplinar acontece de forma pontual, quando duas ou mais disciplinas se juntam no intuito de incitar a troca de seus conhecimentos peculiares, com o objetivo exclusivo de esclarecer ou de resolver um determinado problema. Holland (2008, p. 10) ainda acrescenta que as palavras-chave que indicam as diferenças nestas relações de colaboração podem ser: integração e proximidade. O termo integração está relacionado à colaboração de natureza interdisciplinar, assim como o termo proximidade condiz com a colaboração de natureza multidisciplinar. Para Rogers et al. (2003, p. 3), muitos estudos autointitulados de interdisciplinares, na verdade, trabalham no nível multidisciplinar, isto é, "onde um grupo de pesquisadores de diferentes disciplinas colabora trabalhando em conjunto no mesmo problema para um objetivo comum, mas continuam a fazê-lo usando as teorias, ferramentas e métodos de sua própria disciplina".

No contexto específico da Ciência da Informação, Saracevic (1996, p. 48) entende que esta possui como uma de suas principais características a natureza interdisciplinar, sendo tal natureza introduzida pela própria variedade da formação das pessoas que se ocuparam na resolução dos problemas de informação que deram origem ao campo, tais como engenheiros, bibliotecários, químicos, linguistas, filósofos, psicólogos, matemáticos, cientistas da computação, homens de negócios, dentre outros. Dessa forma, o autor afirma que são vários os campos que mantêm relações interdisciplinares com a Ciência da Informação, porém aqueles que as desenvolveram com maior sig- 
nificância podem ser discriminados em quatro: Biblioteconomia, Ciência da Computação, Ciência Cognitiva e Comunicação.

Entretanto, ressalta-se que a abordagem de Saracevic (1996) está fundamentada na emergência da Ciência da Informação como campo científico a partir dos trabalhos iniciados por Bush (1945), no âmbito da recuperação da informação norte-americana. Se levarmos em consideração apenas este contexto histórico como marco efetivo do surgimento da Ciência da informação há de convir com o autor e dizer que o campo se estabeleceu por meio de relações interdisciplinares com tais disciplinas, principalmente com a Ciência da Computação, tendo em vista sua carga conceitual ter procedido dos avanços tecnológicos da recuperação da informação e, num movimento reverso, ter servido em alguns caminhos com conceitos voltados para a construção de sistemas de recuperação de informação mais eficazes, como por exemplo, a introdução das questões de relevância e semântica a partir da década de 1970 .

Por outro lado, considerando que a Ciência da Informação possui sua emergência no final do Século XIX a partir dos conceitos e práticas de informação oriundas do campo da Documentação de Otlet que, no domínio do conhecimento contemporâneo, desponta como a base social teórica do campo da informação, observa-se uma profícua relação de natureza interdisciplinar entre as duas disciplinas no que diz respeito à integração de conceitos, principalmente no decorrer das extremidades do Século XX, quando as contribuições de Otlet e Frohmann no campo da Documentação, por exemplo, iniciam e modificam respectivamente o curso da produção do conhecimento no campo da informação e, por sua vez, obtêm da própria Ciência da Informação as condições necessárias para a legitimação do discurso da Documentação, abrindo espaço na contemporaneidade para a construção de novos conceitos legítimos da Ciência da Informação, como por exemplo, o do regime de informação.

Nesse sentido, a evolução temporal apresentada até aqui nos permite dizer que a maior parte das relações estabelecidas no campo da Ciência da Informação no período de construção do seu arcabouço científico, entre as décadas de 1940 e 1960 em diante, são de natureza multidisciplinar devido à observação de três aspectos: o primeiro diz respeito à orientação destas relações que, taticamente, estavam voltadas para a construção de um campo científico para a atividade de informação capaz de atender aos interesses diversos da comunidade científica norte-americana. O segundo está relacionado à incipiência da integração de conceitos entre as disciplinas que se reuniram no intuito de resolver o problema da cientificidade do campo, tendo em vista permanecerem durante o esforço utilizando teorias, ferramentas e métodos inerentes às suas próprias disciplinas, não havendo uma apropriação recíproca. Por fim, o terceiro consiste nas consequências destas relações para 
o campo da Ciência da Informação que, mesmo com a incidência da cognição nas décadas de 1970 e 1980, não se desenvolveu de forma consistente no âmbito teórico-metodológico.

Destarte, reconhece-se que outras disciplinas além da Documentação estabeleceram relações interdisciplinares com a Ciência da Informação, em contextos específicos, como é o caso da Biblioteconomia. Além disso, acredita-se que as demais disciplinas protagonistas do esforço científico estadunidense podem vir a estabelecer relações interdisciplinares com a Ciência da Informação no momento em que conceitos, teorias ou métodos da Ciência da Informação forem incorporados em seus respectivos campos, o que se espera que aconteça de forma natural nos próximos caminhos. Mais que isso, o cenário informacional contemporâneo é propício para o desenvolvimento de outras relações interdisciplinares no campo, principalmente no âmbito das disciplinas sociais e humanas, tais como a Filosofia, a Comunicação, a Psicologia e, principalmente, a Sociologia, que começa a enxergar a Ciência da Informação como um campo próspero para os estudos sociais da informação, colaborando assim para o surgimento de novas disciplinas, como por exemplo, a Sociologia da Informação que já pode encontrar seu ponto de partida nas concepções de Garfinkel (2008).

Sendo assim, com base nas distinções ora apresentadas, entende-se que o campo da Ciência da Informação tanto se caracteriza pelas relações interdisciplinares quanto pela colaboração de natureza multidisciplinar, sendo esta última encontrada com maior frequência nos estudos desenvolvidos em sua história. Na contemporaneidade, é comum que os estudos da Ciência da Informação necessitem se apropriar de conhecimentos específicos de outras disciplinas para a resolução de problemas de informação diversos, todavia, sem que haja o caráter de transformação/integração conceitual, como ocorre, por exemplo, com as ações de informação aplicadas na área da gestão, mediação ou tecnologias da informação. Portanto, compreende-se que os discursos tradicionais que definem a Ciência da Informação, em sua totalidade, como uma "ciência interdisciplinar", podem dar lugar a abordagens relativas e contextuais, fortalecendo a concepção de campo flexível e propício para a construção de novos conhecimentos, ampliando a natureza sociocultural da informação e das tecnologias digitais.

\section{Conclusões}

Resgatando a metáfora das rotas de navegação, demonstradas ainda na introdução deste trabalho, observa-se que os caminhos traçados entre as duas 
perspectivas de início do campo da informação e o advento de seu desenvolvimento teórico-social podem ser relacionados com as rotas de loxodromia e ortodromia entre dois pontos. A concepção de loxodromia da Ciência da Informação possui como ponto de partida os trabalhos de Otlet no campo da Documentação no período que marca o fim do Século XIX e início do Século XX que, em sintonia com algumas reflexões da Biblioteconomia, mantiveram-se alinhados ao longo do tempo com os pressupostos sociais da produção do conhecimento, já eminentes no final do Século XX, tendo como um de seus principais marcos de chegada, as contribuições de Frohmann no próprio campo da Documentação, por meio das reflexões sobre o caráter social e material da informação, bem como os estudos dos regimes de informação.

Nesse traçado, os ângulos constantes que serviram como referências em cada segmento para o rumo da navegação possibilitaram a formação de relações interdisciplinares no campo da informação (Documentação e Ciência da Informação), permitindo a integração de conceitos entre as disciplinas, corroborando com o desenvolvimento dos dois lados e, principalmente, permanecendo ajustados em um único sentido: o social.

Em relação à rota de ortodromia da Ciência da Informação, considerada mais rápida e ao mesmo tempo complexa, os ângulos foram traçados e ajustados durante o curso da navegação, de acordo com os interesses da tripulação, na maioria das vezes em sentidos opostos ao rumo social, mas gloriosos pelas descobertas apresentadas que, por repercutirem de forma positiva, tornaram cada vez mais distante o que parecia ter sido alcançado. Nessa perspectiva, o ponto de partida corresponde ao trabalho de Bush no âmbito da recuperação da informação que impulsionou os estudos científicos para o fenômeno da informação e, por sua vez, o campo da Ciência da Informação. No decorrer deste percurso, os ângulos traçados estiveram voltados para inúmeros segmentos, entre eles a cientificidade do campo, os sistemas de informação e os usuários de informação.

Contudo, mesmo apresentando características interdisciplinares em alguns segmentos deste caminho, a rota de ortodromia conservou seus pressupostos teóricos no traçado dos azimutes, isto é, o tecnicismo e a objetividade, desconsiderando as peculiaridades do caminho, constituindo em grande escala relações multidisciplinares do ponto de vista social da produção do conhecimento que, agora, após ser avistado como norte, também passa a fazer parte dos ângulos de navegação deste traçado.

Dessa forma, entende-se que a direção da produção do conhecimento na Ciência da Informação deve estar orientada para o rumo social, ou seja, para as interações entre os sujeitos nos diversos contextos em que a informação se situa, a fim de se evitar caminhos desgastantes e perigosos. Ao navegar em 
linhas paralelas (equinociais) ou meridionais, as rotas de loxodromia e ortodromia podem se ajustar, possibilitando a coerência de diferentes perspectivas de estudo, abrindo alguns horizontes distintos, porém agregadores para ambas. Por falar em coerência e ajuste entre as rotas, referimo-nos simplesmente aos pontos de partida e de visada (chegada), sem a intenção de reduzir as inúmeras opções de escolha dos traçados que permitem a ligação entre os pontos, até porque este modo de pensar não tem mais espaço no campo flexível da Ciência da Informação. Acredita-se que a existência de rotas distintas, desde que coerentes com o rumo de navegação, é salutar para o campo, pois os novos conhecimentos se devem aos pensamentos inusitados.

Por fim, ressalta-se que este trabalho foi construído através do ponto de vista social deste autor que, ao reconhecer a importância de outros autores e disciplinas para o desenvolvimento social da Ciência da Informação, resolveu fazer um recorte voltado para o campo da Documentação, destacando os seus maiores feitos. Portanto, acredita-se que novas configurações interdisciplinares e multidisciplinares podem ser apresentadas em estudos posteriores, com ênfase para outras disciplinas relevantes, ou até mesmo em sentido de contestação das ideias até aqui apresentadas, mas sem dúvidas com o objetivo de fortalecimento do rumo social. Essa é a nossa principal intenção.

\section{REFERÊNCIAS}

Araújo, C. A. A. (2009), "Correntes teóricas da ciência da informação”, Ciência da Informação, 38 (3), 192-204.

Barreto, A. de A. (1992), "A informação no mundo da técnica", ECO/ Publicação de Pós-Graduação da Escola de Comunicação da Universidade Federal do Rio de Janeiro, 1 (1), 27-34.

Borko, H. (1968), "Information science: what is this?", American Documentation, 19, 3-5.

Braman, S. (2004), The emergent global information policy regime, Hampshire: Palgrave.

Buckland, M. K. (1991), "Information as thing", en Journal of the American Society for Information Science, New York, 45 (5), 351-360.

Bush, V. (1945), "As we may think", The Atlantic Monthly, 176 (1), 119. Accessible [en linea]: http://www.theatlantic.com/unbound/ flashbks/computer/bushf.html Consulta: 10 de dezembro de 2011.

Butler, L. P. (1933), An introduction to library science, Chicago: University of Chicago Press.

Cronin, B. (2008), "The sociological turn in Information Science", Journal of Information Science, 34 (4), 465-475. 
Day, R. E. (1997), "Paul Otlet's Book and the Writing of Social Space", Journal of American Society for Information Science, 48 (4), 310-317.

Ducheyne, S. (2005), "Paul Otlet's Theory of Knowledge and Linguistic Objectivism”, Knowledge Organization, 32 (3), 110-116.

Ekbia, H. (2009), "Information in action: a situated view", Proceedings of the American Society for Information Science and Technology, 46 (1), 1-11.

Figueiredo, N. (1996), "Paul Otlet e o centenário da FID”, Organização do conbecimento e sistemas de classificação, Brasília: IBICT.

Freire, G. H. de A. (2006), "Ciência da Informação: temática, história e fundamentos”, Perspectivas em Ciência da Informação, Belo Horizonte, 11 (1), 6-19.

Frohmann, B. (1995), "Taking information policy beyond Information Science: applying the actor network theory for connectedness: information, systems, people, organizations", Annual Conference for Information Science, 23, 7-10. Accessible [en linea]: http://www.fims.uwo.ca/people/faculty/frohmann/actor.htm Consulta: 01 de outubro de 2011.

- (2008), "O caráter social, material e público da informação", M.

S. L. Fujita, R. M. Marteleto e M. L. G. de Lara, A dimensão epistemológica da Ciência da Informação e suas interfaces técnicas, politicas e institucionais nos processos de produção, acesso e disseminação da informação, São Paulo: Cultura Acadêmica Ed.; Marília: Fundepe, 17-34.

Garfinkel, H. (2008), Rumo a uma Teoria Sociológica da Informação, Boulder, CO: Publishers paradigma.

González de Gómez, M. N. (1999), "O caráter seletivo das ações de informação”, INFORMARE-Cadernos do Programa de Pós-Graduação em Ciência da Informação, Rio de Janeiro, 5 (2), 7-30.

— (2002), "Novos Cenários Políticos para a Informação", Ciencia da Informação, Brasília, 3 (1), 27-40.

- (2007), "Para una reflexión epistemológica sobre la ciencia de la información”, Signo y Pensamiento, Bogotá, 26 (50), 46-61.

_ (2012), "Regime de informação: construção de um conceito", Informação \& Sociedade: Estudos, João Pessoa, 22 (3), 43-60.

Holland, G. A. (2008), "Information science: an interdisciplinary effort?", Journal of Documentation, 64 (3), 7-23.

Hjørland B. (1995), "Toward a new horizon in information science: domain analysis", Journal of the American Society for Information Science, 46 (6), 400-425.

- (2002), "Epistemology and the socio-cognitive perspective in Information Science”, JASIST, 53 (4), 257-270.

Klein, J. T.; Newell, W. (1998), "Advancing interdisciplinary study", W. Newell (ed.), Interdisciplinarity: Essays from the Literature, College Entrance Examination Board, NewYork. 
Kling, R. (1990), "More Information, Better Jobs? Occupational Stratification and Labor Market Segmentation in the United States' Information Labor Force”, The Information Society, 7 (2), 77-107.

Linares Columbié, R. (2010), "Epistemología y ciencia de la información: repensando un diálogo inconcluso", Acimed, Havana, 21 (2). Acessible [em linea], http://www.acimed.sld.cu/index.php/ acimed/article/viewArticle/52/18 Consulta: 22 de outubro de 2012.

Mikhailov, A. I. (1959), "Finalidades y problemas de la información científica", Boletin de la UNESCO para las bibliotecas, Havana, 13, 267-270.

Moran, J. (2002), Interdisciplinarity, London: Routledge.

Otlet, P. (1934), Traité de documentation: Le livre sur Le livre, théorie ETpretiquet, Bruxelles: Mundaneum.

Pinheiro, L. V. R. (1997), A Ciência da Informação entre sombra e luz: domínio epistemológico e campo interdisciplinar, Tese (Doutorado em Comunicação e Cultura), Rio de Janeiro: Escola de Comunicação da UFRJ.

_ (2002), "Gênese da ciência da informação ou sinais anunciadores da nova área”, M. A. Aquino, O campo da ciência da informação, João Pessoa: UFPB, 61-86.

Rabello, R. A. (2012), "Ciência da Informação como objeto: epistemologias como lugar de encontro", Perspectivas em Ciência da Informação, 17 (1), 2-36.

Rayward, W. B. (1994), "Visions of Xanadu: Paul Otlet (1868-1944) and Hypertext", Journal of the American Society for Information Science, 45 (4), 235-250.

Rogers, Y.; Scaife, M. e Rizzo, A. (2003), "Interdisciplinarity: an emergent or engineered, process?”, CSRP Technical Report, 556, University of Sussex, Brighton, 1-25.

Saracevic, T. (1996), "Ciência da informação: origem, evolução e relações”, Perspectivas em Ciência da Informação, Belo Horizonte, 1 (1), 41-62.

Shannon, C. E. e Weaver, W. (1949), The mathematical theory of communication, Urbana: University of Illions Press.

Shera, J. (1970), Sociological foundations of librarianship, New York: Asia Publishing House.

Taylor, R. (1966), "Professional aspects of information science and technology", ARIST, 1 (1), 15-40.

Tiratel, S. R. (2008), "Paul Otlet, el antepasado olvidado revisión bibliográfica: I. Aspectos biográficos, históricos e teóricos”, Información, cultura y sociedad, Buenos Aires, 18, 13-36.

Wiener, N. (1948), Cybernetics: or control and communication in the animal and the machine, Paris: Camb Mass MIT Press. 